\title{
CUESTIONAMIENTOS AL SISTEMA DE DETRACCIONES EN EL PERÚ, EN PARTICULAR AL “INGRESO COMO RECAUDACIÓN”
}

\author{
Jose Luis Miní Miranda. ${ }^{1}$
}

\begin{abstract}
RESUMEN
El Sistema de detracciones tiene por finalidad generar fondos para el pago de obligaciones tributarias, costas y gastos del procedimiento de Cobranza Coactiva, y se sustenta en el deber de colaboración y control del obligado para combatir los niveles de evasión que existen en el Impuesto General a las Ventas. Siendo de naturaleza administrativa, se regula por la Ley de Procedimiento Administrativo General.

Sin embargo, existe una serie de cuestionamientos al Sistema de detracciones, entre las principales, la complejidad del sistema, la diversidad de las tasas e imprecisión de los conceptos comprendidos, así como la inseguridad jurídica que se genera por la permanente modificación de sus normas y supuestos.

Por otro lado, si bien con el Sistema de detracciones no se aseguran fines recaudatorios definitivos, pues éstos se depositan en una cuenta a nombre del proveedor, y existe un mecanismo de libre disposición para los depósitos que no se usen en un determinado tiempo, el numeral 9.3 del artículo $9^{\circ}$ del DL $N^{\circ} 940$ faculta a la SUNAT a solicitarle al Banco de la Nación el traslado de los depósitos de las cuentas corrientes de detracciones hacia los fondos de la Administración en calidad de "recaudación"”; para destinarse al pago de deudas tributarias presentes o futuras del proveedor, por lo que este mecanismo tiene naturaleza tributaria, y en consecuencia, debe someterse a lo dispuesto por el Código Tributario aprobado por DS N $133-2013-E F$.
\end{abstract}

Como en el caso del Sistema de detracciones, también existen cuestionamientos al mecanismo de ingreso como recaudación, tanto a los supuestos que lo motivan, como al procedimiento mismo, por lo que en ambos casos propondremos las modificaciones pertinentes.

\section{PALABRAS CLAVE}

Sistema de Detracciones. SPOT. Ingreso como Recaudación. Administración Tributaria. SUNAT. Clave SOL. Inconsistencias.

\section{ABSTRACT}

The tax withholding system aims at generating funds to pay for tax obligations, costs and expenses associated to coercive debt collection proceedings and is founded on taxpayer's duty of collaboration and surveillance in order to combat Sales Tax evasion. Since it has an administrative nature, it is governed by the General Administrative Proceedings Act.

Nevertheless, there are a number of challenges posed on the Withholding System, such as the complexity of the system, the multiplicity of rates, and vagueness of many of the terms, as well the legal uncertainty resulting from the constant amendments to the rules and assumptions.

On the other hand, the Tax Withholding System does not secure final collection since the monies are deposited in a bank account under the name of taxpayer. Moreover, there is a mechanism by which holder can use the funds that are not committed within a given period of time. In light of this, subsection 9.3 of Article 9 of DL 940 empowers the Tax Administration (SUNAT) to petition the National Bank (Banco de la Nación) to transfer such funds deposited in the tax withholding checking account to the Tax Administration's accounts, as "final collection," so as to pay taxpayer's current and future tax debts. This mechanism has a taxation nature and, consequently, is governed by the provisions of the Tax Code approved by DS 133-2013-EF.

Like the Tax Withholding System, the revenue mechanism for collection purposes is challenged regarding both its rationale and procedures. Hence, this paper proposes appropriate amendments for the two areas.

\section{KEY WORDS}

Tax Withholding System. SPOT. Revenue from Collection. Tax Administration. SUNAT. SOL Password. Inconsistencies.

1 Abogado, Magister en Regulación por la UPC, Socio del Estudio Miní Miranda Abogados, Ex Intendente Nacional de Operaciones de la SUNAT, Docente UNIFE y USMP.

2 Recaudación definitiva. 
Cuestionamientos AL sistema de DETRACCIONES (SPOT)

Desde el año 2002, se viene aplicando el sistema de pago de obligaciones tributarias con el Gobierno Central, conocido como "sistema de detracciones"3, en virtud del cual el adquirente de ciertos bienes o servicios gravados con el Impuesto General a las Ventas ${ }^{4}$, debe depositar una parte del precio total (detracción) en una cuenta del Banco de la Nación perteneciente al proveedor, que le servirá exclusivamente para el pago de su obligaciones tributarias con el Gobierno Central, y que podrá liberar, si no se agotan en cuatro, dos meses o quince días ${ }^{5}$, y no presenta deudas con la Administración Tributaria.

El SPOT tiene por finalidad generar fondos para el pago del IGV, el Impuesto a la Renta, ONP, ESSALUD, entre otros tributos, así como de las Multas e intereses, costas y gastos del procedimiento de Cobranza Coactiva. En efecto, el monto detraído resulta intransmisible e inembargable, y sólo puede utilizarse para el pago de deudas tributarias que constituyan ingreso del Tesoro Público, por lo que sólo la SUNAT podría embargarlos en un procedimiento de cobranza coactiva.

Se encuentra regulado por el Decreto Legislativo (DL) $\mathrm{N}^{\circ} 940$, publicado el 20.12.2003, modificado por el DL N ${ }^{\circ} 954$ y, últimamente, por el DL N ${ }^{\circ} 1110^{6}$; todos recogidos en el Decreto Supremo (DS) $N^{\circ}$ 155-2004-EF y normas modificatorias - TUO del DL $\mathrm{N}^{\circ} 940$ publicado el 14.11.2004; y por la Resolución de Superintendencia (RS) $\mathrm{N}^{\circ}$ 183-2004/ SUNAT, publicada el 15.08.2004 y vigente desde el 15.09.2004 y normas modificatorias ${ }^{7}$.

Sobre su naturaleza jurídica, al no tratarse de un tributo no extingue deudas tributarias, y si se incumple con el pago, no puede aplicársele intereses moratorios. Tampoco puede ser materia de cobranza coactiva. Respecto del adquirente, al no ser sujeto pasivo de la relación jurídica tributaria, no califica ni como contribuyente ni como responsable (agente de retención o percepción $\left.{ }^{8}\right) .{ }^{9}$

Este sistema se sustenta en el deber de colaboración y control del obligado para evitar la evasión que se produce en la comercialización de una serie de productos cuya cadena de distribución presenta los más altos índices de informalidad, así como en la prestación de determinados servicios gravados con el IGV.

En efecto, el Tribunal Constitucional $^{10}$ mediante Sentencia $\mathrm{N}^{\circ}$ 03769-2010-PA/TC ha señalado que "La detracción se constituye en un deber singular y distin-

En adelante SPOT.

En adelante IGV.

Artículo $25^{\circ}$ de la R.S. $N^{\circ} 183-2004 /$ SUNAT señala:

"Artículo 25.- Solicitud de libre disposición de los montos depositados

25.1 Procedimiento general

Para solicitar la libre disposición de los montos depositados en las cuentas del Banco de la Nación se observará el siguiente procedimiento:

Los montos depositados en las cuentas que no se agoten durante cuatro (4) meses consecutivos como mínimo, luego que hubieran sido destinados al pago de los conceptos señalados en el artículo 2 de la Ley, serán considerados de libre disposición.

Tratándose de sujetos que tengan la calidad de buenos contribuyentes, de conformidad con lo dispuesto en el Decreto Legislativo $N^{\circ} 912$ y normas reglamentarias, o la calidad de agentes de retención del Régimen de Retenciones del IGV, regulado por la Resolución de Superintendencia $N^{\circ}$ 037-2002/SUNAT y normas modificatorias, el plazo señalado en el párrafo anterior será de dos (2) meses consecutivos como mínimo, siempre que el titular de la cuenta tenga tal condición a la fecha en que solicite a la SUNAT la libre disposición de los montos depositados en las cuentas del Banco de la Nación. (...)

25.2 Procedimiento especial

Sin perjuicio de lo indicado en el numeral 25.1, tratándose de operaciones sujetas al Sistema referidas a los bienes señalados en los Anexos 1 y 2, excepto los comprendidos en los numerales 20 y 21 del Anexo 2:

El titular de la cuenta podrá solicitar ante la SUNAT la libre disposición de los montos depositados en las cuentas del Banco de la Nación hasta en dos (2) oportunidades por mes dentro de los primeros tres (3) días hábiles de cada quincena, siempre que respecto del mismo tipo de bien señalado en el Anexo 1 y Anexo 2, según el caso (...)."

6 DL que modifica el Texto Único Ordenado del DL № 940, las Leyes № 27605 y 28211, y el Decreto Ley N²25632, publicado el 20. 06. 2012.

7 Modificaciones que van desde la RS N ${ }^{\circ}$ 207-2004/SUNAT, publicada el 10.09.2004 y vigente a partir del 15.09.2004, hasta la RS No 265-2013/SUNAT, publicada el 28.08.2013 y vigente a partir del 01.09.2013.

8 Artículo $10^{\circ}$ del Código Tributario.

9 Cfr. ALVA MATTEUCCI, Mario: 2009.

10 En adelante TC. 
to a los regímenes de retención y percepción de tributos ya que el agente detractor no entrega al fisco el monto detraído dejándose de producir un efecto inmediato en la recaudación fiscal. En cambio en las figuras de la retención y percepción, (...) el agente retenedor o perceptor sí entrega los montos directamente a la administración tributaria produciéndose un impacto inmediato en la recaudación fiscal. Es decir, estamos ante un deber que colabora o apoya indirectamente a la recaudación de tributos, pudiéndole considerar como un deber administrativo."

Si bien el TC sustenta su postura considerando que con el SPOT no se aseguran fines recaudatorios definitivos, pues existe un mecanismo de libre disposición, no es el único destino que eventualmente podrían tener los montos depositados, ya que de acuerdo al numeral $9.3 \mathrm{del}$ artículo $9^{\circ}$ del DL $N^{\circ} 940$, SUNAT puede solicitarle al Banco de la Nación el traslado de los montos de las cuentas corrientes de detracciones hacia los fondos de la Administración en calidad de "recaudación"; a fin de que sea destinada al pago de la deuda tributaria del proveedor, incluso con vencimiento posterior al depósito realizado, por lo cual sí tiene una repercusión inmediata en la recaudación fiscal ${ }^{11}$.

Complejidad del sistema, diversidad de tasas e imprecisión de los conceptos

Aun tomando en consideración que se trata de figuras jurídicas diferentes, revisemos el pronun- ciamiento del TC sobre la constitucionalidad del Impuesto a las Transferencias Financieras ${ }^{12}$ y el sistema de recaudación anticipada de Percepciones.

Respecto del ITF, mediante STC $N^{\circ}$ 0004-2004-Al/TC el TC señaló “(...) Se trata, pues, de reglas de orden público tributario, orientadas a finalidades plenamente legítimas, cuales son contribuir, de un lado, a la detección de aquellas personas que, dada su carencia de compromiso social, rehuyen la potestad tributaria del Estado (...)."

Asimismo, refiriéndose al sistema de recaudación anticipada de Percepciones, en la STC $\mathrm{N}^{\circ}$ 6626-2006-PA/TC, indicó que en un Estado Social y Democrático de Derecho como el nuestro, “(...) el ciudadano ya no tiene exclusivamente el deber de pagar tributos, concebido según el concepto de libertades negativas propio del Estado Liberal, sino que asume deberes de colaboración con la Administración, los cuales se convertirán en verdaderas obligaciones jurídicas. En otras palabras, la transformación de los fines del Estado determinará que se pase de un deber de contribuir, basado fundamentalmente en la capacidad contributiva, a un deber de contribuir basado en el principio de solidaridad. (...)"

Agregó el TC que, “(...) en un contexto como el peruano, pueda entenderse razonable y necesaria -por lo menos hasta conseguir el pleno cumplimiento de sus fines- la existencia de regímenes de colaboración con la Administración, como en el caso de las percepciones del IGV. (...)" No obstante, precisa, que ello "(...) no significa que el Legislador o la Administración Tributaria tengan carta abierta para sustentar su actuación apelando de manera indiscriminada a la extrafiscalidad en la lucha contra la evasión tributaria. (...)"

Si bien en el ITF, en los Regímenes de Percepción y Retención y en el SPOT, las obligaciones se sustentan en el deber de colaboración o de control del sujeto obligado, en el caso del SPOT debió considerarse el hecho de que quien detrae no actúa ni como contribuyente ni como responsable, como sí ocurre en los otros tres casos.

Por el contrario, en vez se aplicársele una tasa única y establecerse un mecanismo ágil y neutro como en el caso del ITF o de las Retenciones, o cuando menos tasas homogéneas, como ocurre con las Percepciones, se aprobó un mecanismo impreciso y muy complejo. En efecto, en el SPOT las tasas oscilan entre $1.5 \%$ y $15 \%$ para el caso de bienes afectos, y entre $4 \%$ y $12 \%$ para servicios afectos, como se indica en los Anexos I, II y III de la RSN ${ }^{\circ} 183-2004 / S U N A T$ y modificatorias.

El tema de las tasas se complica, si consideramos que además existen otras normas que también incluyen bienes o servicios al ámbito del SPOT, con tasas diferenciadas a las señaladas en los anexos, por ejemplo, el caso del Arroz pilado, incorporado mediante la Tercera Disposición 
Complementaria y Final de la Ley $\mathrm{N}^{\circ} 28211$.

En tal virtud, y conforme al Principio de Simplificación en la Recaudación ${ }^{13}$, deben estandarizarse las tasas y aplicarse tasas únicas, o cuando menos homogéneas. Es en esta línea, que recientemente la SUNAT, mediante RS N ${ }^{\circ}$ 265-2013/SUNAT, publicada el 28. 08.2013 y vigente desde el 01.09.2013, modificó la RS No 183-2004-SUNAT y la RS $N^{\circ}$ 250-2012-SUNAT, modificando las tasas de los Anexos I, II y III, lo que significó un tímido avance en el esfuerzo de simplificar el sistema.

Por otro lado, de acuerdo con las innumerables consultas formuladas a SUNAT, se puede inferir que existe una imprecisa determinación de los conceptos que comprenden los bienes $\mathrm{y} / \mathrm{o}$ servicios incluidos en el sistema, lo que dificulta saber con precisión el porcentaje de detracción que le corresponde a cada operación, y aplicar tasas diferentes sólo por errores involuntarios ${ }^{14}$ supone una multa equivalente al $100 \%$ del monto no detraído, y como castigo adicional, la imposibilidad de ejercer el derecho al crédito fiscal, al menos hasta la acreditación del depósito del $100 \%$ de la detracción. ${ }^{15}$

Cabe destacar, que resulta curioso, que en reiteradas ocasiones, la SUNAT haya tenido que consultarle al Instituto Nacional de Estadística e In- formática (INEI), si determinada actividad se encuentra o no comprendida en un Clasificación Internacional Industrial Uniforme (CIIU) a fin de responder si estaba o no sujeta a detracción, como si pretendiera que el contribuyente le consulte al INEI para saber si la operación se encuentra sujeta al sistema ${ }^{16}$ o para saber con precisión la tasa correspondiente.

Esa es la razón por la que algunos piensan que las condiciones establecidas en el SPOT, más que un pretendido "sistema de control" sea más bien una onerosa obligación formal, que conlleva a una serie de contingencias tributarias ${ }^{17}$.

Siendo así, consideramos que existe una imperiosa necesidad de reformar el SPOT, tomando en cuenta las dificultades de los sujetos involucrados, y evitando que el compromiso de contribuir vaya ligado a una serie de complicaciones que se conviertan en multas y otras sanciones.

\section{Inseguridad Jurídica}

En sus inicios el SPOT se aplicó únicamente a la venta de bienes, luego la $\mathrm{RSN}^{\circ}$ 183-2004/ SUNAT amplió su aplicación a una lista determinada de bienes y servicios, que se encuentran detallados en los Anexos I, II y III de la mencionada Resolución. Durante todos estos años, dichos Anexos han sufrido una serie de modificaciones e incorporaciones.

Desde el 01.10.2006, mediante la RSN ${ }^{\circ} 073-2006 / S U N A T$ y normas modificatorias, se extendió su aplicación al transporte de bienes realizado por vía terrestre gravado con IGV. A su vez, mediante RS Nº 057-2007/SUNAT y normas modificatorias, se incorpora al sistema el servicio de transporte público de pasajeros realizado por vía terrestre, cuando el vehículo en el que se presta el servicio transite por las garitas o puntos de peaje expresamente señalados en el Anexo.

En los últimos años, desde el 01.11.2012, mediante RS $\mathrm{N}^{\circ}$ 249-2012/SUNAT se amplía su aplicación a la venta de determinados bienes exonerados del IGV, y mediante RS N ${ }^{\circ} 250-2012$ / SUNAT, publicada el 31.10.2012y vigente a partir del 01.11.2012, se incorporó a los espectáculos públicos gravados con el IGV.

Finalmente, desde el 01.02.2013, mediante RS $\mathrm{N}^{\circ}$ 022-2013/SUNAT, se modifica la RS No 183-2004/SUNAT a fin de aplicar el SPOT a la primera venta de inmuebles que realicen los constructores de los mismos, con una tasa del $4 \%$ sobre el valor de venta del inmueble, y mediante RS $N^{\circ}$ 265-2013/ SUNAT, de 28.08.2013, se modifica la RS No 183-2004-SUNAT y la RS Nº 250-2012-SUNAT que reguló el Sistema de Pago de Obligaciones Tributarias aplicable a los Espectáculos Públicos.

13 Numeral 1.13 de la Norma IV del Título Preliminar de la LPAG, aprobada mediante Ley $N^{\circ} 27444$.

14 Y con ello exponerse a la multa respectiva, la misma que equivale al $100 \%$ del monto no detraído, y como castigo adicional, a la imposibilidad de ejercitar el crédito fiscal, al menos hasta la acreditación del depósito.

15 Siendo que esto genera inconsistencias con la declaración jurada, también ocasiona el ingreso como recaudación que tratamos más adelante.

16 Entre otros, puede apreciarse en INFORME N ${ }^{\circ}$ 100-2012-SUNAT/4B0000.

17 Cfr. PAJUELO LÓPEZ, Antonio: 2012. 
A la fecha se encuentran vigentes 33 normas aplicables al SPOT y se han derogado 18 , por lo que prácticamente es imposible conocer el contenido de las mismas, peor aún si como se ha indicado los supuestos no son claros, evidenciándose una absoluta inseguridad jurídica de la normatividad aplicable en cada caso concreto.

\section{Cuestionamientos al ingreso COMO RECAUDACIÓN}

En el numeral 9.3 del artículo $9^{\circ}$ del DL N ${ }^{\circ} 940^{18}$, se establecen las causales o supuestos que habilitan a la SUNAT a ingresar como recaudación los montos depositados en la cuenta de detracciones del contribuyente ${ }^{19}$, y en el artículo $26^{\circ}$ de la RS $N^{\circ}$ $183-2004 /$ SUNAT $^{20}$, se precisan las causales y el procedimiento a seguir.
Al respecto, resulta necesario destacar algunos cuestionamientos a este mecanismo de recaudación.

\section{De los supuestos}

\section{Inconsistencia entre las de- claraciones presentadas y el depósito}

El literal a) del numeral 9.3 del Artículo $9^{\circ}$ del DL N ${ }^{\circ} 940$ señala que el Banco de la Nación ingresará como recaudación los montos depositados, de conformidad con el procedimiento que establezca la SUNAT, cuando las declaraciones presentadas del titular de la cuenta contengan información no consistente con las operaciones por las cuales se hubiera efectuado el depósito.

Agrega la referida norma, que los montos ingresados como re- caudación serán destinados al pago de las deudas tributarias, las costas y gastos, cuyo vencimiento, fecha de comisión de la infracción o detección de ser el caso, así como la generación de las costas y gastos, se produzca, incluso, con anterioridad o posterioridad a la realización de los depósitos correspondientes ${ }^{21}$.

Por su parte, el Artículo $79^{\circ}$ el Código Tributario, aprobado por DS $\mathrm{N}^{\circ}$ 133-2013-EF ${ }^{22}$, referido a la Orden de Pago Presuntiva, señala que si los deudores tributarios no declararan ni determinaran, o habiendo declarado no efectuaran la determinación de los tributos que se determinen en forma mensual, así como de pagos a cuenta, se tomará como referencia la suma equivalente al mayor importe de los últimos doce (12) meses en los que se

18 Modificado por el DL N¹110, publicado el 20 Junio 2012.

19 "Artículo 9.- Destino de los montos depositados

(...) 9.3 El Banco de la Nación ingresará como recaudación los montos depositados, de conformidad con el procedimiento que establezca la SUNAT, cuando respecto del titular de la cuenta se presente cualquiera de las siguientes situaciones:

a) Las declaraciones presentadas contengan información no consistente con las operaciones por las cuales se hubiera efectuado el depósito, excluyendo las operaciones a que se refiere el inciso c) del artículo 3.

b) Tenga la condición de domicilio fiscal no habido de acuerdo con las normas vigentes.

c) No comparecer ante la Administración Tributaria o comparecer fuera del plazo establecido para ello, siempre que la comparecencia esté vinculada con obligaciones tributarias del titular de la cuenta.

d) Haber incurrido en cualquiera de las infracciones contempladas en el numeral 1 del artículo 174, numeral 1 del artículo 175, numeral 1 del artículo 176, numeral 1 del artículo 177 o numeral 1 del artículo 178 del Código Tributario. (...)

20 "Artículo 26.- Causales y procedimiento de ingreso como recaudación

26.1 Los montos depositados serán ingresados como recaudación cuando respecto del titular de la cuenta se presente cualquiera de las situaciones previstas en el numeral 9.3 del artículo 9 de la Ley, para lo cual se deberá tener en cuenta lo siguiente:

a) Las situaciones previstas en el numeral 9.3 del artículo 9 de la Ley, serán aquéllas que se produzcan a partir de la vigencia de la presente resolución. Lo dispuesto no se aplicará a la situación prevista en el inciso a) del numeral 9.3 del artículo 9 de la Ley y a la infracción contemplada en el numeral 1 del artículo 176 del Código Tributario a la que se refiere el inciso d) del citado numeral, en cuyo caso se tomarán en cuenta las declaraciones cuyo vencimiento se hubiera producido durante los últimos doce (12) meses anteriores a la fecha de la verificación de dichas situaciones por parte de la SUNAT.

b) El titular de la cuenta incurrirá en la situación prevista en el inciso a) del numeral 9.3 del artículo 9 de la Ley cuando se verifiquen las siguientes inconsistencias, salvo que éstas sean subsanadas mediante la presentación de una declaración rectificatoria, con anterioridad a cualquier notificación de la SUNAT sobre el particular: (...).

c) La situación prevista en el inciso b) del numeral 9.3 del artículo 9 de la Ley, se presentará cuando el titular de la cuenta tenga la condición de domicilio fiscal no habido a la fecha de la verificación de dicha situación por parte de la SUNAT.

d) Tratándose de la infracción contenida en el numeral 1 del artículo 176 del Código Tributario a la que se refiere el inciso d) numeral 9.3 del artículo 9 de la Ley, se considerará la omisión a la presentación de las declaraciones correspondientes a los siguientes conceptos, salvo que el titular de la cuenta subsane dicha omisión hasta la fecha de verificación por parte de la SUNAT: (...).

21 Último párrafo del numeral 9.3 del Artículo $9^{\circ}$ del Decreto Legislativo $\mathrm{N}^{\circ} 940$.

22 En adelante Código Tributario. 
pagó o determinó el tributo o el pago a cuenta.

Como puede apreciarse, el Código Tributario exige la emisión y notificación de un valor, y la posible discusión mediante los recursos impugnativos a los que tiene derecho el contribuyente, en otras palabras dispone que sólo es posible cobrarse deudas tributarias reales impagas, y no posibilidades que surjan de simples inconsistencias, que en muchos de los casos no son reales y congruentes, sino sólo depósitos en exceso o en defecto realizado por los obligados a efectuar la detracción.

Si en el Código Tributario se encuentra previsto este procedimiento para los casos en que los contribuyentes no hubieran determinado correctamente sus obligaciones tributarias, resulta cuestionable lo dispuesto por el Numeral 9.3 del Artículo $9^{\circ}$ del DL N ${ }^{\circ} 940$ y la RS No 1832004/SUNAT, que le permite a la SUNAT apropiarse de los depósitos de las detracciones obviando las garantías previstas en el Código Tributario.

\section{La condición de "no habido" - Inapropiada notificación de las "Service"}

El literal b) del numeral 9.3 del Artículo $9^{\circ}$ del DL $N^{\circ} 940$ señala que el Banco de la Nación ingresará como recaudación los montos depositados, de conformidad con el procedimiento que establezca la SUNAT, cuando la condición de domicilio fiscal del titular de la cuenta sea "no habido" de acuerdo con las normas vigentes.
Por su parte, el numeral $6.1 \mathrm{del}$ Artículo $6^{\circ}$ del DS N ${ }^{\circ}$ 041-2006$E F$, señala que la SUNAT procederá a requerir al deudor tributario que adquirió la condición de no hallado para que cumpla con declarar o confirmar su domicilio fiscal hasta el último día hábil del mes en el que se le efectúa el requerimiento, bajo apercibimiento de asignarle la condición de "no habido".

Agrega el numeral 6.3, que los deudores tributarios que no cumplan con declarar o confirmar su domicilio fiscal dentro del plazo señalado en el numeral 6.1, adquirirán la condición de "no habido" en la fecha en que se efectúe la publicación a que se refiere el numeral 8.1 del Artículo 8, sin que para ello sea necesario la emisión y notificación de acto administrativo adicional alguno.

Asimismo, en el numeral 4.1 del Artículo $4^{\circ}$ del DS $\mathrm{N}^{\circ} 041$ 2006-EF se establecen los requisitos para obtener la condición del "no hallado", sin que para ello sea necesaria la emisión y notificación de acto administrativo adicional alguno, si al momento de notificar los documentos mediante correo certificado o mensajero, o al efectuar la verificación del domicilio fiscal, se presenta alguna de las siguientes situaciones: 1. Negativa de recepción de la notificación o negativa de recepción de la constancia de la verificación del domicilio fiscal por cualquier persona capaz ubicada en el domicilio fiscal, 2. Ausencia de persona capaz en el domicilio fiscal o éste se encuentre cerrado, o 3. No existe la dirección declarada como domicilio fiscal.

Precisa el numeral 4.2 del citado artículo, que para determinar la condición de "no hallado" las situaciones señaladas en los incisos 1 y 2 del numeral 4.1 deben producirse en tres (3) oportunidades en días distintos.

En conclusión, para que se adquiera la condición de "no habido" no debe habérsele podido notificar al titular de la cuenta cuando menos 3 veces, y además no haber respondido al requerimiento de la Administración Tributaria de declarar o confirmar su domicilio.

El inconveniente que podemos notar sobre esta causal, es que una institución privada denominada "Service" contratada por SUNAT es la que se encarga de efectuar todas las notificaciones, por lo que muchas veces la condición de "no habido" se adquiere no porque no se encuentra al contribuyente en su domicilio, sino por una incorrecta notificación de los "Services".

\section{No comparecer y algunas in- fracciones - Doble imposición de sanciones}

Los literales c) y d) del numeral 9.3 del Artículo $9^{\circ}$ del DL N ${ }^{\circ}$ 940 señalan que el Banco de la Nación ingresará como recaudación los montos depositados, de conformidad con el procedimiento que establezca la SUNAT, cuando titular de la cuenta no comparece ante la Administración Tributaria o comparece fuera del plazo establecido ${ }^{23}$, 0 incurre en cualquiera de las

23 Siempre que la comparecencia esté vinculada con obligaciones tributarias del titular de la cuenta. Esta infracción se encuentra sancionada con una Multa equivalente al 50\% de la UIT. 
infracciones contempladas en los numerales 1 de los artículos $174^{\circ}, 175^{\circ}, 176^{\circ}, 177^{\circ}$ o $178^{\circ}$ del Código Tributario.

En este caso, el contribuyente quedará sometido a una doble sanción por el incumplimiento, pues además de tener que asumir la multa prevista en la Tabla de Sanciones anexa al Código Tributario; se encontrará sometido a la disposición del ingreso como recaudación de sus cuentas de detracciones.

Se vulnera así el Principio Non bis in idem, implícitamente enunciado en el inciso 13) del artículo $139^{\circ}$ de la Constitución Política del Perú de $1993^{24}$ que dispone "La prohibición de revivir procesos fenecidos con resolución ejecutoriada"; y además previsto de forma expresa en el numeral 10 del artículo $230^{\circ}$ del Capítulo II - del Procedimiento Sancionador de la Ley de Procedimiento Administrativo General, aprobada por Ley $\mathrm{N}^{\circ} 27444^{25}$ de la forma siguiente:

"10. Non bis in idem.- No se podrán imponer sucesiva 0 simultáneamente una pena y una sanción administrativa por el mismo hecho en los casos en que se aprecie la identidad del sujeto, hecho y fundamento.

Dicha prohibición se extiende también a las sanciones administrativas, salvo la concurrencia del supuesto de continuación de infracciones a que se refiere el inciso $7 .{ }^{26}$ "
Como es de verse, el hecho de imponer una multa por haber incurrido en alguna de las infracciones mencionadas para caso materia del presente análisis, así como disponer el ingreso como recaudación de la cuenta de detracciones del contribuyente al fisco, acarrearía una doble imposición de sanciones, pues se estaría vulnerando lo dispuesto por los preceptos legales (CPP y LPAG), toda vez que, no se condeciría con el principio constitucional y legal del Non bis in ídem."

Por otro lado, cuando la Administración dispone el ingreso en recaudación, por haberse producido alguna de las causales previstas en el numeral 9.3 del Artículo $9^{\circ}$ del $\mathrm{DL} \mathrm{N}^{\circ} 940$, ingresa todo el monto de las detracciones que se encuentran depositados en ese momento. Por ejemplo, si se motivara en la infracción establecida en el Art. $178^{\circ}$ numeral 1 del Código Tributario por no haber declarado todos los ingresos, o haber aumentado indebidamente el crédito fiscal, podría ocurrir que la omisión de impuestos sea $\mathrm{S} / .15$, y el monto depositado en las cuentas de detracciones que se ingresan como recaudación sea S/. 100,000, por lo que en estos casos la medida es por demás excesiva.

Por lo tanto, el sistema debiera establecer una correspondencia entre la causal y el ingreso como recaudación, para evitar situaciones como la descrita.
Por último, consideramos, que esta causal desincentiva la subsanación voluntaria y el consecuente acogimiento al Régimen de Gradualidad ${ }^{27}$, toda vez que la simple comisión de las infracciones previstas en los numerales 1 de los artículos citados, supone el ingreso como recaudación.

\section{Del procedimiento}

Inadecuada comunicación a través de la notificación mediante el buzón electrónico (Clave SOL)

El Artículo $3^{\circ}$ de la RS $\mathrm{N}^{\circ}$ 014-2008-SUNAT, referido a los actos administrativos materia de notificación señala que "los actos administrativos que se señalan en el anexo que forma parte de la presente resolución, podrán ser materia de notificación a través de Notificaciones SOL. Asimismo, que la SUNAT incorporará en el citado anexo, de manera gradual, los actos administrativos que podrán ser notificados de esta forma.

Por su parte, el Numeral $6^{28} \mathrm{del}$ Anexo de la referida resolución, que regula la notificación de los actos administrativos por medios electrónicos, señala que tanto la Comunicación que da inicio del procedimiento como la Resolución de Intendencia que dispone el ingreso como recaudación podrán notificarse a través de Notificaciones SOL.

El Artículo $7^{\circ}$ de la citada resolución precisa que la afiliación

\footnotetext{
4 En adelante CPP.

En adelante LPAG.

Numeral modificado por el Artículo $1^{\circ}$ del Decreto Legislativo № 1029, publicado el 24 Junio 2008.

Régimen de Gradualidad aprobado por RS Nº 063-2007/SUNAT, y normas modificatorias.

Procedimiento incorporado por el Artículo $2^{\circ}$ de la Resolución № 135-2009-SUNAT, publicada el 21. 06. 2009.
} 
a Notificaciones SOL podrá comprender la totalidad o alguno(s) de los tipos de documento que figuren en el anexo, mientras que el Artículo 8 dispone que la desafiliación de Notificaciones SOL opera respecto de la totalidad de los tipos de documento por los que registró su afiliación y surtirá efectos a partir del día calendario siguiente al registro de la desafiliación.

De acuerdo con las normas citadas, pareciera que el contribuyente tuviera derecho a indicar qué documentos quisiera que se le notifique a través de la Clave SOL, cuando en realidad el contribuyente sólo se afilia, y es la SUNAT quien determina qué documentos notifica por esta vía. Así, mediante Anexo de la RS $N^{\circ}$ 014-2008-SUNAT ha dispuesto que tanto la Comunicación como la Resolución de Intendencia que dispone el ingreso como recaudación se notifiquen a través de la Clave SOL.

Por su parte, el inciso b) del Artículo $104^{\circ}$ del Código Tributario establece que:

“Artículo 104.- FORMAS DE NOTIFICACIÓN

La Notificación de los actos administrativos se realizará, indistintamente, por cualquiera de las siguientes formas:

(...)

b) Por medio de sistemas de comunicación electrónicos, siempre que se pueda confirmar la entrega por la misma vía.
Tratándose del correo electrónico u otro medio electrónico aprobado por la SUNAT o el Tribunal Fiscal que permita la transmisión o puesta a disposición de un mensaje de datos o documento, la notificación se considerará efectuada al día hábil siguiente a la fecha del depósito del mensaje de datos o documento.

$(\ldots)^{29}$.

A tenor de lo dispuesto en el Código Tributario, la SUNAT se ha sentido liberada de tener que acreditar la confirmación de los documentos que notifica a través de sistemas de comunicación electrónicos, siendo para ella suficiente que los mismos lleguen a la bandeja de entrada de la Clave SOL.

No compartimos dicha interpretación, no sólo porque el Código Tributario exige la confirmación como requisito, sino además, porque dada la transcendencia de estos documentos, la notificación por medios electrónicos no es el mecanismo idóneo.

Finalmente, el Artículo $20^{\circ}$ de la LPGA precisa que:

“Artículo 20.- Modalidades
de notificación
20.1 Las notificaciones serán
efectuadas a través de las
siguientes modalidades, se-
gún este respectivo orden de
prelación:
20.1 .1 Notificación personal
al administrado interesado o
afectado por el acto, en su
domicilio.

20.1.2 Mediante telegrama, correo certificado, telefax; o cualquier otro medio que permita comprobar fehacientemente su acuse de recibo y quien lo recibe, siempre que el empleo de cualquiera de estos medios hubiese sido solicitado expresamente por el administrado ${ }^{30}$.

(...)

Como es de verse, tanto el Código Tributario como la LPAG establecen la necesidad que se pueda confirmar la recepción de la notificación, requisito que no es recogido en la RS $\mathrm{N}^{\circ}$ 014-2008-SUNAT y su Anexo, amparado en el segundo párrafo del literal b) del artículo $104^{\circ}$ del Código Tributario.

Por otro lado, encontramos una diferencia sustancial entre el Código Tributario y la LPAG, pues en el primero se establece que "la Notificación de los actos administrativos se realizará, indistintamente, por cualquiera de las siguientes formas" 31 , mientras que en la LPAG $^{32}$ se señala que "las notificaciones serán efectuadas a través de las siguientes modalidades, según este respectivo orden de prelación". Consideramos que el Código Tributario tendría que adecuarse a los principios contendidos en la LPAG, y consecuentemente a lo dispuesto por la Constitución Política del Perú de 1993.

En efecto, no debe quedar a criterio de la Administración la forma de notificación que se

\footnotetext{
Inciso modificado por el Artículo $3^{\circ}$ del Decreto Legislativo $N^{\circ} 1113$, publicado el 5 de Julio de 2012.

Numeral modificado por el Artículo 1 del DL N 1029, publicado el 24 Junio 2008.

Primer párrafo del Artículo $104^{\circ}$ del Código Tributario.

Primer párrafo Artículo $20^{\circ}$ de la LPAG.
} 
debe usar, sino que debe establecerse en forma específica, sobre todo si se trata de notificaciones que van a afectar los recursos económicos del titular de la cuenta de detracciones. Somos de la opinión, que dada las implicancias que genera la notificación de la Comunicación y Resolución de Intendencia que dispone el ingreso como recaudación, debe notificarse exclusivamente mediante acuse de recibo en el domicilio del contribuyente.

Por último, el que se notifiquen dichos documentos mediante la Clave SOL obliga a que se tenga que revisar la cuenta electrónica permanentemente. Esa parece ser la idea, pues según el Artículo $6^{\circ}$ de la RS N ${ }^{\circ}$ 014-2008-SUNAT, el deudor tributario debe consultar periódicamente su buzón electrónico cuando por afiliarse a Notificaciones SOL deba recibir las notificaciones de los actos administrativos que figuren en su anexo.

Si bien la norma indica "periódicamente", lo cierto es que tendría que hacerse diariamente si quiere evitarse alguna contingencia tributaria, pues la SUNAT sólo otorga 3 días hábiles para sustentar la inexistencia de la causal que alega, señalando que, vencido el plazo sin que se sustente dicha inexistencia, se procederá a disponer el ingreso como recaudación de los fondos de la cuenta de detracciones del proveedor o prestador del servicio.

\section{Inadecuada motivación}

El procedimiento de ingreso como recaudación de los fondos de la cuenta detracciones se inicia con la notificación de SUNAT de la Comunicación de Intendencia a través de la Clave SOL, mediante la que se informa que "se habría detectado una de las causales previstas en el numeral 9.3 del Artículo $9^{\circ}$ del DL N ${ }^{\circ} 940 "$. Por tal razón, conceden un plazo de 3 días hábiles para que se pueda sustentar la inexistencia de la causal verificada. Entrecomillamos el motivo de la notificación, pues es exactamente lo que informan, que se ha detectado la causal prevista en el inciso a), b), c) o d) de la norma citada, sin ninguna explicación adicional que permita conocer la causa, pero además ejercer la defensa apropiadamente.

Lo mismo ocurre con la Resolución de Intendencia que dispone el ingreso como recaudación de los fondos depositados en la cuenta de detracciones, pues la Administración no agrega mayores argumentos que los indicados en la Comunicación y por lo general confirma la causal no aceptando el sustento formulado por el contribuyente.

En efecto, en la STC 0090-2004AA/TC el TC señaló que "el deber de motivación de la administración pública no debe limitarse a utilizar citas legales, que solo hacen referencia a disposiciones en conjunto, pero sin concretar cuál y cómo las mismas amparan la argumentación o análisis de la autoridad pública".

No es indispensable que la motivación sea extensa, puede ser sucinta, sin embargo es imprescindible que sea suficiente, lo importante es que en ella se desvelen las razones que en virtud de los hechos concretos han aconsejado al órgano administrativo resolver en un determinado sentido. La principal tarea que debe exigírsele al autor de la motivación es la comunicación de las razones, pues en la motivación de los actos están involucrados valores esenciales del estado de Derecho ${ }^{33}$.

De igual forma, el TC en la sentencia STC 8495-2006-PA/ TC precisó que "un acto administrativo dictado al amparo de una potestad discrecional legalmente establecida resulta arbitrario cuando sólo expresa la apreciación individual de quien ejerce la competencia administrativa, o cuando el órgano administrativo, al adoptar la decisión, no motiva o expresa las razones que lo han conducido a adoptar tal decisión. De modo que, motivar una decisión no sólo significa expresar únicamente bajo qué norma legal se expide el acto administrativo, sino, fundamentalmente, exponer en forma sucinta -pero suficiente- las razones de hecho y el sustento jurídico que justifican la decisión tomada."

Es por tal razón que a decir de Tomás Fernández Rodríguez, “la motivación de la decisión, comienza, pues, por marcar la diferencia entre lo discrecional y lo arbitrario, y ello, porque si no hay motivación que lo sostenga, el único apoyo de la decisión será la sola voluntad de quien lo adopta, apoyo insuficiente, como es obvio, en un Estado de Derecho" (2008: 81).

Por otro lado, la CPP, en el inciso 5 de su artículo $139^{\circ}$ tam-

33 Rodríguez Arana- Muñoz 2002: 219. 
bién ha incorporado el Principio de Motivación, al señalar que: "Son principios y derechos de la función jurisdiccional: (...) 5. La motivación escrita de las resoluciones judiciales en todas las instancias, excepto los decretos de mero trámite, con medición expresa de la ley aplicable y de los fundamentos de hecho en que se sustentan".

De igual forma, en el art. IV, inciso 1.2, de la LPAG, se indica que la motivación integra el principio del debido procedimiento:

“1.2. Principio del debido procedimiento.- Los administrados gozan de todos los derechos y garantías in herentes al debido procedimiento administrativo, que comprende el derecho a exponer sus argumentos, a ofrecer y producir pruebas y a obtener una decisión motivada y fundada en derecho. La institución del debido procedimiento administrativo se rige por los principios del Derecho Administrativo. La regulación propia del Derecho Procesal Civil es aplicable sólo en cuanto sea compatible con el régimen administrativo".

De acuerdo con la STC 05379 . 2011 “(...) la falta de motivación o su insuficiencia constituye una arbitrariedad e ilegalidad, en la medida en que es una condición impuesta por la Ley № 27444. Así, la falta de fundamento racional suficiente de una actuación administrativa es por sí sola contraria a las garantías del debido procedimiento administrativo."

A pesar que algunos consideran que de acuerdo con la autonomía del Derecho Tributario debe primar el principio de especialidad; el principio del debido procedimiento es aplicable al Derecho Tributario, y no tendría que ser contradictorio, si consideramos que el principio del debido procedimiento es una derivación del principio constitucional del debido proceso, y por lo tanto debe de ser aplicable a todo procedimiento, incluido al procedimiento administrativo tributario, no sólo en razón del carácter de norma suprema de la Constitución, sino además, por la exigencia de su aplicación a todo el ordenamiento jurídico.

En efecto, sendas Sentencias del TC, entre ellas la STC 01412 2007-AA/TC, han señalado que el principio del debido proceso no sólo debe aplicarse al proceso judicial, sino que se extiende a todo tipo de procedimiento:

“(...)el debido proceso está concebido como el cumplimiento de todas las garantías y normas de orden público que deben aplicarse a todos los casos y procedimientos, en cuyo seno se alberga los actos administrativos, a fin de que las personas estén en la posibilidad de defender adecuadamente sus derechos ante cualquier acto del Estado o de los particulares que pueda afectarlos. Queda claro, entonces, que la cláusula fundamental contenida en el artículo 139.3 de la Constitución Política del Perú, no es "patrimonio" exclusivo de los procesos jurisdiccionales, sino que el respeto del contenido del debido proceso se hace extensivo a los procesos administrativos públicos o privados."

En consecuencia, si bien el principio de motivación como precepto constitucional es aplicable a los procesos judiciales, por interpretación sistemática también es aplicable a los procedimientos administrativos, entre ellos, a los tributarios.

Por otro lado, la motivación también se encuentra recogida en el art. 3 de la LPAG, como uno de los requisitos de validez de los actos administrativos:

"art. 3.- Son requisitos de validez de los actos administrativos:

(....)

4. Motivación.- El acto administrativo debe estar debidamente motivado en proporción al contenido y conforme al ordenamiento jurídico".

Asimismo, si revisamos el Código Tributario se le exige a la administración la motivación de sus actos, por ejemplo como requisito para la emisión de una Resolución de determinación o de $\mathrm{Multa}^{34}$, y cuya inobservancia constituye causal de anulabilidad $^{35}$, así como requisito para la emisión de los actos de la Administración Tributaria, los que deben constar en los respectivos instrumentos 0 documentos $^{36}$.

\footnotetext{
Art. $77^{\circ}$ núm. 7 y el penúltimo párrafo del mismo artículo del CT.

Art. $109^{\circ}$ del CT.

Art. $103^{\circ}$ del CT.
} 
Como es de verse, ninguna de estas garantías constitucionales y legales se consideran en el procedimiento de ingreso como recaudación, a pesar que suponen una afectación económica al contribuyente.

\section{Vulneración del derecho de defensa de los contribuyentes}

La facultad de la Administración Tributaria de disponer el ingreso como recaudación de las cuentas de detracciones implica también una vulneración del derecho de defensa pues tratándose de un asunto administrativo y no tributario, sólo puede recurrirse a los recursos administrativos regulados en la LPGA, que son resueltos por quien los emite, esto es por la SUNAT, impidiendo que dicho acto sea revisado por un órgano independiente como el Tribunal Fiscal $^{37}$, lo que es contrario al Estado Social y Democrático de Derecho.

En efecto, de acuerdo con el ordenamiento jurídico actual, contra la Resolución de Intendencia que dispone el ingreso como recaudación, y ante el mismo órgano que dictó el primer acto que es materia de impugnación, puede interponerse Recurso de Reconsideración ${ }^{38}$, que debe sustentarse en nueva prueba $^{39}$. El mencionado recurso podrá interponerse dentro del plazo de 15 días hábiles siguientes a su notificación, esto es a su depósito en la bandeja de la clave SOL. Siendo un recurso opcional, no es un requisito para presentarse el Recurso de Apelación.
Por su parte, el Recurso de Apelación ${ }^{40}$, debe sustentarse en diferente interpretación de las pruebas presentadas o en cuestiones de puro derecho, debiendo dirigirse ante la misma autoridad que expidió el acto que se impugna para que lo eleve al superior jerárquico. Para la interposición de este recurso se tiene también 15 días hábiles desde notificada la resolución que dispuso el ingreso como recaudación o que declaró infundado el recurso de reconsideración.

Sin embargo, la forma en que se notifica la Resolución de Intendencia que dispone el ingreso como recaudación podría vulnerar el derecho de defensa si el contribuyente no revisa permanentemente su cuenta electrónica, y deja transcurrir el plazo de los 15 días sin haber interpuesto el recurso respectivo, perdiendo toda posibilidad de cuestionar la decisión de la Administración.

Esta situación se agrava si el contribuyente no se entera de las comunicaciones y resoluciones emitidas por SUNAT, precisamente por las dificultades que surgen con la notificación mediante la Clave SOL, no pudiendo impugnar dichos actos, cuando era posible demostrar que no existía inconsistencia, posibilitándose que la SUNAT se apropie de un monto que el contribuyente pudo usar o recuperar.

De lo expuesto, en la medida que los montos ingresados como recaudación son imputados a cualquier deuda tributaria, costas y gastos, deben ser revisados por un órgano independiente y distinto de quien lo dispone, sólo así se asegurará el respeto al derecho de defensa, y consecuentemente un pronunciamiento acorde a ley.

Cabe mencionar que en reiterada jurisprudencia, el TF se ha inhibido de resolver las quejas ocasionadas por este tipo de actuaciones, señalando que el procedimiento de ingreso como recaudación constituye una actuación meramente administrativa regulada por la LPAG, en vista que a su criterio esta materia carece de carácter tributario. Sin embargo, el TF, no considera que dicha recaudación sirve para el pago de obligaciones tributarias, por lo que en realidad es de carácter tributario, y en consecuencia debe regirse por los procedimientos establecidos en el Código Tributario.

No obstante, existen intentos por revertir este criterio. En la RTF N ${ }^{\circ}$ 07808-11-2012, de fecha 15.05.2012, el TF indica que el cuestionamiento no se orienta a que se haya dispuesto el ingreso como recaudación de los fondos de la cuenta de detracciones (pues en ese caso considera no tener competencia para emitir pronunciamiento, por tratarse de un asunto que corresponde ser tramitado de acuerdo con las normas de la LPAG), sino que más bien, dicho monto fue imputado a una deuda tributaria respecto de la cual no se emitió el valor de cobranza respectivo.

\footnotetext{
En adelante TF.

Artículo $208^{\circ}$ de la LPAG.

En los casos de actos administrativos emitidos por órganos que constituyen única instancia no se requiere nueva prueba.

40 Artículo $209^{\circ}$ de la LPAG.
} 
En ese sentido, afirma que al ser un aspecto de naturaleza tributaria, por estar referido a la cancelación de una deuda tributaria mediante un procedimiento que la quejosa considera que no se encuentra arreglado a ley, y toda vez que no existe otra vía mediante la cual la quejosa pueda discutir dicha imputación, pues no se ha emitido acto administrativo alguno susceptible de ser impugnado, considera que le corresponde analizar y pronunciarse acerca de la legalidad de la imputación efectuada. ${ }^{41}$

Si bien se trata de avances, lo cierto es que, el ingreso como recaudación sirve al pago de la deuda tributaria, tiene carácter tributario; y en consecuencia, tendría que ser regulado por el Código Tributario.

\section{CONCLUSIONES}

a. El ingreso como recaudación de los montos de las cuentas de detracciones para el pago de la deuda tributaria, incluso con vencimiento posterior a la fecha del ingreso es de naturaleza tributaria, y en consecuencia tendría que estar regulado por el Código Tributario.

b. El ingreso como recaudación debe sustentarse en valores que además puedan ser cuestionados mediante los recursos impugnativos previstos en el Código Tributario.

c. Debe excluirse la comisión de las infracciones contempladas en los numerales 1 de los artículos $174^{\circ}, 175^{\circ}$, $176^{\circ}, 177^{\circ}, 178^{\circ}$ y numeral 7 del artículo $177^{\circ}$ del Códi- go Tributario como causales para el ingreso como recaudación.

d. La Comunicación y Resolución de Intendencia que disponen el ingreso como recaudación deben notificarse exclusivamente mediante acuse de recibo en el domicilio del contribuyente, y además motivarse suficientemente, más allá de una cita legal, con la argumentación o análisis que las motivan.

e. Debe establecerse límites a los montos que se ingresan como recaudación de acuerdo a la causal que lo motiva.

\section{RECOMENDACIONES}

a. Reformar el SPOT, para evitar que el deber de colaboración o control del obligado, le genere contingencias tributarias.

b. Estabilizar y simplificar el sistema normativo del SPOT que le permita al obligado conocerlo y aplicarlo correctamente. Asimismo, homogenizarse las tasas y propender a que sean tasas únicas.

\section{Biblografía}

ALVA MATTEUCCI, Mario.

2009. ¿Sabe usted cuándo los fondos de las cuentas de detracciones del banco de la nación ingresan como recaudación?.

Blog de Mario Alva Matteucci. (http:/ /blog.pucp.edu.pe/ item / 69380 / sabe-ustedcuando-los-fondos-de-lascuentas-de-detraccionesdel-banco-de-la-nacion- ingresan-como-recaudacion) (Consulta 15 Agosto).

FLORES GALLEGOS, Jorge Raúl. 2013. ¿Son válidas las imputaciones automáticas de los fondos recaudados que realiza la SUNAT?, pp. I-24 y I-25. En: Revista Actualidad Empresarial $\mathrm{N}^{\circ} 272$ - Primera Quincena de Febrero 2013.

GARCÍA NOVOA, César. (2009). "El concepto de tributo". Perú: Tax Editor S.A.. p. 217.

HUAMANÍ CUEVA, Rosendo. (2007). "Código Tributario Comentado". Perú: Jurista Editores E.I.R.L.. Quinta Edición. p. 79.

ROCANO, Roberto Pablo.

2011. El ingreso como recaudación de los fondos depositados en la cuenta de detracciones.

Blog de Roberto Rocano. (http:/ /blog.pucp.edu.pe/ item/130279/el-ingreso-como-recaudacion-de-los-fondos-depositados-en-la-cuenta-de-detracciones)(Consulta 22 Julio).

PAJUELO LÓPEZ, Antonio A.

2012. Análisis respecto a la naturaleza del Sistema de Detracciones.

En: Estudio Jurídico Contable - “GESTIÓN”E.I.R.L..

RUBIO CORREA, Marcial. (2008). "Para conocer la Constitución de 1993". Perú: Editorial DESCO. pp. 98.

VILLANUEVA GUTIÉRREZ, Walker. (2009). "Estudio del Impuesto al Valor Agregado en el Perú". Perú: Tax Editor S.A.. p. 450.

41 Cfr. FLORES GALLEGOS, Jorge Raúl: 2013. 